\title{
Potencial probiótico in vitro de bactérias ácido-láticas isoladas de queijo-de-minas artesanal da Serra da Canastra, MG
}

\author{
[Probiotic potential of lactic acid bacteria isolated from Minas artisanal cheese \\ from Serra da Canastra, MG]
}

\author{
H.H.S. Costa ${ }^{1}$, M.R. Souza ${ }^{1}$, L.B. Acúrcio ${ }^{1 *}$, A.F. Cunha ${ }^{1}$, M.F.S. Resende ${ }^{1}$, Á.C. Nunes ${ }^{2}$ \\ ${ }^{1}$ Escola de Veterinária - Universidade Federal de Minas Gerais - Belo Horizonte, MG \\ ${ }^{2}$ Instituto de Ciências Biológicas - Universidade Federal de Minas Gerais - Belo Horizonte, MG
}

\begin{abstract}
RESUMO
O potencial probiótico in vitro de 12 amostras de bactérias ácido-láticas (11 Lactobacillus spp. e uma Weissella paramesenteroides), isoladas de queijo-de-minas artesanal da Serra da Canastra, foi investigado. Essas amostras foram caracterizadas in vitro quanto à susceptibilidade a antimicrobianos, antagonismo contra microrganismos de referência patogênicos e não patogênicos e sensibilidade a $\mathrm{pH}$ gástrico e sais biliares. Apenas L. rhamnosus B4, W. paramesenteroides C10 e L. rhamnosus D1 apresentaram resistência a menor número de antimicrobianos (ceftazidima, oxacilina, estreptomicina e vancomicina). Todas as amostras apresentaram atividade antagonista frente a todas as bactérias patogênicas testadas e não inibiram as bactérias não patogênicas. Todas as amostras foram resistentes ao pH gástrico (2.0). Alguns microrganismos mostraram pouca inibição do crescimento em presença de sais biliares, enquanto outros foram moderadamente ou altamente inibidos. L. rhamnosus B4, W. paramesenteroides $\mathrm{C} 10$ e L.rhamnosus D1 apresentaram o melhor potencial probiótico de acordo com os testes in vitro realizados.
\end{abstract}

Palavras-chave: queijo-de-minas artesanal, bactéria ácido-lática, potencial probiótico

\begin{abstract}
The in vitro probiotic potential of twelve samples of lactic acid bacteria (eleven Lactobacillus spp. and one Weissella paramesenteroides) isolated from Minas artisanal cheese from Serra da Canastra was evaluated for their antimicrobial susceptibility, antagonistic activity against pathogenic and lactic acid bacteria, as well as for their tolerance to gastric $p H$ and biliary salts. Only L. rhamnosus B4, W. paramesenteroides $C 10$, and $\mathrm{L}$. rhamnosus Dl showed resistance to tested antimicrobials (ceftazidime, oxacillin, streptomycin, and vancomycin). All samples showed antagonism against all pathogenic bacteria tested and did not inhibit the growth of nonpathogenic samples. Regarding gastric pH tolerance, all samples showed low inhibition at $\mathrm{pH}$ 2. The tolerance to biliary salts varied from low to great among tested samples. L. rhamnosus $\mathrm{B} 4 \mathrm{~W}$. paramesenteroides $\mathrm{C10}$, and $\mathrm{L}$. rhamnosus $\mathrm{D} 1$ showed the best probiotic potential revealed by their in vitro test results.
\end{abstract}

Keywords: Minas artisanal cheese, lactic acid bacteria, probiotic potential

\section{INTRODUÇÃO}

A utilização de bactérias ácido-láticas e outros microrganismos em alimentos lácteos fermentados é difundida ao longo da história. Muitos são os benefícios que esses

Recebido em 22 de março de 2012

Aceito em 5 de maio de 2013

*Autor para correspondência (corresponding author)

E-mail: leonaruto@hotmail.com microrganismos podem conferir aos alimentos, como a conservação de suas propriedades nutricionais, o incremento no sabor e a capacidade de conferir maior segurança alimentar ao produto (Gilliland, 1985). 
Alimentos que propõem melhorias à saúde do consumidor, principalmente contendo microrganismos ditos probióticos, são amplamente comercializados. Microrganismos como as bactérias ácido-láticas - podem ter propriedades que auxiliam na saúde e bem-estar dos consumidores. Porém, concentração adequada nos alimentos - que devem ser consumidos regular e frequentemente - em que são veiculados e sobrevivência durante a sua validade são fatores cruciais para que cheguem aos seus sítios de ação, possibilitando a manifestação de seus efeitos benéficos (Grajek et al., 2005).

A Agência Nacional de Vigilância Sanitária (Anvisa, 2008) determina parâmetros para o enquadramento de um produto como probiótico, como concentração mínima de microrganismos probióticos no produto $\left(10^{8}\right.$ a $\left.10^{9} \mathrm{UFC} / \mathrm{mL}\right)$ comprovada até o final da validade do produto, resistência a sais biliares e acidez gástrica da cultura comprovada por testes laboratoriais, utilização de uma das espécies recomendadas ou de uma espécie fora da lista que seja comprovadamente probiótica, além de outros pormenores referentes à rotulagem do produto.

O queijo-de-minas artesanal é produzido, na maioria das vezes, do leite cru e apresenta grande variabilidade na microbiota, podendo até apresentar microrganismos patogênicos e deteriorantes possivelmente danosos ao consumidor. Pesquisas envolvendo alimentos produzidos artesanalmente têm como principal objetivo a caracterização da microbiota e a verificação das propriedades probióticas dos microrganismos, principalmente bactérias ácidoláticas (Alexandre et al., 2002; Coppola et al., 2005). Tendo em vista a importância histórica, cultural e socioeconômica da produção do queijo-de-minas artesanal no estado de Minas Gerais e o elevado risco ao qual a sua população consumidora pode estar submetida, ressalta-se a relevância de buscar alternativas para solucionar esta situação e garantir a qualidade e a segurança alimentar do produto.

O desenvolvimento de pesquisas visando à ampliação do conhecimento microbiológico e das potencialidades probióticas das bactérias ácido-láticas possibilita novas perspectivas para a melhoria da qualidade do queijo e da sua segurança alimentar, preservando a sua microbiota desejável. O principal objetivo deste trabalho foi iniciar o processo de seleção de espécies de bactérias ácido-láticas de queijo-deminas artesanal da Serra da Canastra - MG, a fim de possibilitar futuros avanços na utilização desses microrganismos.

\section{MATERIAL E MÉTODOS}

As bactérias ácido-láticas utilizadas foram previamente isoladas de queijo-de-minas artesanal da Serra da Canastra e identificadas ao nível molecular por PCR ARDRA 16S-23S (Tisala-Timisjarvi e Alatossava, 1997) no trabalho de Resende et al. (2011). As amostras foram inicialmente isoladas em meio de cultura ágar MRS (Difco, Detroit, Estados Unidos), sendo uma identificada como Weissella paramesenteroides e as demais identificadas como Lactobacillus distribuídas em quatro espécies: L. casei (amostras B5, A21 e C7), L. rhamnosus (A23, B4 e D1), L. plantarum (A17, B7, B19 e D13) e L. hilgardii (D8).

O antibiograma foi realizado em duplicata, com três repetições, de acordo com a técnica adaptada de susceptibilidade a antimicrobianos por difusão da droga em discos (Charteris et al., 1998b). As amostras de microrganismos isolados e selecionados foram cultivadas em ágar MRS (Difco, Detroit, Estados Unidos), em aerobiose $\left(37^{\circ} \mathrm{C}, 24\right.$ a $\left.48 \mathrm{~h}\right)$. Fragmentos das colônias crescidas foram transferidas para tubos contendo $3,5 \mathrm{~mL}$ de salina $0,85 \% \quad(0,85 \% \quad \mathrm{NaCl})$ até alcançarem 0,5 na escala McFarland $\left(10^{8}\right.$ $\mathrm{UFC} / \mathrm{mL}$ ). Em seguida, utilizando-se swabs, os microrganismos foram inoculados sobre a superfície de placas de Petri do tipo pizza contendo ágar MRS (Difco, Detroit, Estados Unidos). Logo após, foram distribuídos os discos (Oxoid, Basingstoke, Inglaterra) contendo os antimicrobianos (com suas concentrações predeterminadas pelo fabricante de acordo com a orientação da Anvisa, 2005): ceftazidima (30 $\mu \mathrm{g})$, clindamicina $(2 \mu \mathrm{g})$, ciprofloxacina $(5 \mu \mathrm{g})$, eritromicina $(15 \mu \mathrm{g})$, gentamicina $(10 \mu \mathrm{g})$, oxacilina $(1 \mu \mathrm{g})$, penicilina $(10 \mathrm{U})$, estreptomicina $(30 \mu \mathrm{g})$, tetraciclina $(30 \mu \mathrm{g})$ e vancomicina $(30 \mu \mathrm{g})$. As placas foram novamente incubadas $\left(37^{\circ} \mathrm{C}, 24 \mathrm{~h}\right) . \quad \mathrm{O}$ controle de qualidade dos discos foi realizado com uma amostra de Escherichia coli ATCC 25922. Após a incubação, com auxílio do paquímetro digital 
Mitutoyo Digimatic Caliper (Mitutoyo Sul Americana Ltda., São Paulo, Brasil), foram feitas as leituras dos diâmetros dos halos de inibição. Os resultados foram submetidos a uma classificação qualitativa dos microrganismos como sensíveis, moderadamente sensíveis ou resistentes às drogas antimicrobianas testadas (Charteris et al., 1998b).

O teste de antagonismo in vitro das bactérias ácido-láticas contra microrganismos indicadores foi realizado em triplicata, com duas repetições, adaptando-se a técnica de Tagg et al. (1976). Dentre as amostras isoladas e identificadas, duas foram selecionadas para participarem do teste de antagonismo in vitro como reveladoras, juntamente com as amostras de referência, a fim de se verificarem possíveis atividades inibitórias entre bactérias do queijo de onde foram isoladas. Microrganismos isolados dos queijos coletados na Serra da Canastra (Lactococcus sp. B12 e L. rhamnosus B25) e bactérias de referência (Staphylococcus aureus ATCC 29313, Escherichia coli ATCC 25922, Listeria monocytogenes ATCC 15313, Salmonella enterica sorovar Typhimurium ATCC 14028 e $L$. fermentum ATCC9338) foram inoculados duas vezes (a $37^{\circ} \mathrm{C}$ por $24 \mathrm{~h}$ ) em caldo BHI (Oxoid, Basingstoke, Inglaterra), MRS (Difco, Detroit, Estados Unidos) e M17 (Difco, Detroit, Estados Unidos), respectivamente, para amostras de referência patogênicas, amostras de Lactobacillus e amostra de Lactococcus sp. B12.

As amostras de microrganismos isolados e selecionados foram ativadas duas vezes em caldo MRS (Difco, Detroit, Estados Unidos), em aerobiose, a $37^{\circ} \mathrm{C}$ por $24 \mathrm{~h}$. Em seguida, $5 \mu \mathrm{L}$ de cada cultivo foram colocados sobre o centro da superfície de uma placa de Petri, contendo ágar MRS (Difco, Detroit, Estados Unidos). As placas foram, então, incubadas, em aerobiose, a $37^{\circ} \mathrm{C}$ por $48 \mathrm{~h}$, formando os spots. Após este período, clorofórmio foi colocado nas tampas das placas, agindo por 30 minutos, a fim de eliminar os microrganismos que cresceram, porém mantendo as prováveis substâncias inibidoras, produzidas pelas bactérias, difundidas no ágar. A seguir, $3,5 \mathrm{~mL}$ de ágar semissólido $(0,75 \%)$, contendo $7,5 \mu \mathrm{L}$ das bactérias reveladoras mencionadas anteriormente, foram vertidos sobre as placas contendo os spots das amostras. Então, as placas foram incubadas $\left(37^{\circ} \mathrm{C}, 24 \mathrm{~h}\right.$, em aerobiose). Por fim, a leitura dos halos de inibição foi realizada com um paquímetro digital Mitutoyo Digimatic Caliper (Mitutoyo Sul Americana Ltda., São Paulo, Brasil). Os resultados demonstraram comportamento não normal, e, assim, para comparação das médias dos halos de inibição, o teste de Kruskal-Wallis foi aplicado (Sampaio, 2002).

Os testes de sensibilidade ao $\mathrm{pH}$ gástrico e aos sais biliares in vitro foram realizados em triplicata, com duas repetições, adaptando-se a técnica de Walker e Gilliland (1993). As amostras de microrganismos isolados e selecionados foram cultivadas duas vezes em caldo MRS (Difco, Detroit, Estados Unidos). Em seguida, a densidade óptica (OD) do inóculo a ser utilizado de cada cultura ativada foi determinada em espectrofotômetro Spectrophotometer, modelo UV 2000 (Molecular Devices, Califórnia, Estados Unidos), com comprimento de onda de $600_{\mathrm{nm}}$. O volume do inóculo de cada amostra foi adicionado a $1 \mathrm{~mL}$ de salina $0,85 \%$ pH 2 e pH 7 e incubado a $37^{\circ} \mathrm{C}$, por três horas. Após esse período, $10 \mu \mathrm{L}$ de cada um dos inóculos em pH 2 e pH 7 foram transferidos para tubos tipo Eppendorf, obtendo-se, para cada amostra, dois tubos. A seguir, foi preparada a microplaca de ELISA de fundo chato, com 96 poços. Nos poços, foram colocados $200 \mu \mathrm{L}-$ retirados do tubo Eppendorf com inóculo - em solução salina pH 2 (pH gástrico) e $200 \mu \mathrm{L}$ em solução salina pH 7 (controle). Então, foram realizadas leituras na OD $620_{\mathrm{nm}}$, com intervalo de 30 minutos, durante $12 \mathrm{~h}$ de incubação a $37^{\circ} \mathrm{C}$, no espectrofotômetro Microplate Spectrophometer, modelo SpectraMax 340 (Molecular Devices). O pH gástrico foi obtido por meio da adição de ácido clorídrico $(\mathrm{HCl}) 1 \mathrm{M}$ e mensuração simultânea do pH em pHmetro digital de bancada (mPA-210, Piracicaba, São Paulo, Brasil) até que fosse atingido o $\mathrm{pH}$ desejado (2). O percentual de inibição do crescimento foi calculado nos tempos de seis e 12 horas pela fórmula: (1-ApH 2/ApH 7)x100, sendo ApH 2: absorbância do inóculo em solução salina pH 2 (gástrico); $\mathrm{ApH} 7$ : absorbância do inóculo em solução $\mathrm{pH} 7$ (controle), de acordo com Mota et al. (2006). A diferença para o teste de sensibilidade aos sais biliares é que não houve incubação prévia por três horas, sendo as amostras colocadas em microplaca de ELISA com 96 poços em presença de caldo MRS (Difco, Detroit, Estados Unidos) 
puro (controle) e caldo MRS (Difco, Detroit, Estados Unidos) com 0,3\% de oxgall (Difco, Detroit, Estados Unidos). Os inóculos foram padronizados à semelhança do que foi feito para o teste anterior. O percentual de inibição do crescimento foi calculado nos mesmos tempos pela fórmula: (1-ASB/AC)x100, sendo ASB: absorbância da amostra com sais biliares; AC: absorbância da amostra controle.

\section{RESULTADOS E DISCUSSÃO}

Os resultados referentes aos antibiogramas de 12 amostras de bactérias ácido-láticas isoladas de queijo-de-minas artesanal da Serra da Canastra são apresentados na Tab. 1.

Todas as amostras testadas foram sensíveis à clindamicina, eritromicina e tetraciclina. A susceptibilidade a esses antimicrobianos também foi observada em $100 \%$ das amostras de $L$. rhamnosus isoladas de queijo Parmigiano Reggiano (Coppola et al., 2005) e em 100\% das amostras do gênero Lactobacillus isoladas de queijos artesanais produzidos com leite cru na Espanha (Rodríguez-Alonso et al., 2009).

Tabela 1. Perfil de susceptibilidade a antimicrobianos de 12 amostras de bactérias ácido-láticas isoladas de queijo-de-minas artesanal

\begin{tabular}{|c|c|c|c|c|c|c|c|c|c|c|}
\hline \multirow{2}{*}{ Amostra } & \multicolumn{10}{|c|}{ Antimicrobiano } \\
\hline & CAZ & CIP & DA & $\mathrm{E}$ & GN & $\mathrm{OX}$ & $\mathrm{P}$ & $\mathrm{S}$ & $\mathrm{T}$ & VA \\
\hline L. casei A21 & $\mathrm{R}$ & $\mathrm{R}$ & $\mathrm{S}$ & $\mathrm{S}$ & $S$ & $\mathrm{R}$ & MS & $\mathrm{R}$ & $\mathrm{S}$ & $\mathrm{R}$ \\
\hline L. casei B5 & $\mathrm{R}$ & $\mathrm{R}$ & S & $\mathrm{S}$ & $\mathrm{R}$ & $\mathrm{R}$ & $\mathrm{R}$ & $\mathrm{R}$ & $\mathrm{S}$ & $\mathrm{R}$ \\
\hline L. casei $\mathrm{C} 7$ & $\mathrm{R}$ & $\mathrm{R}$ & S & $\mathrm{S}$ & $S$ & $\mathrm{R}$ & MS & $\mathrm{R}$ & $\mathrm{S}$ & $\mathrm{R}$ \\
\hline L. rhamnosus A23 & $\mathrm{R}$ & $\mathrm{R}$ & S & $\mathrm{S}$ & $\mathrm{R}$ & $\mathrm{R}$ & $\mathrm{R}$ & $\mathrm{R}$ & $\mathrm{S}$ & $\mathrm{R}$ \\
\hline L. rhamnosus B4 & $\mathrm{R}$ & MS & S & $\mathrm{S}$ & S & $\mathrm{R}$ & MS & $\mathrm{R}$ & $\mathrm{S}$ & $\mathrm{R}$ \\
\hline L. rhamnosus D1 & $\mathrm{R}$ & MS & S & $\mathrm{S}$ & S & $\mathrm{R}$ & $\mathrm{S}$ & $\mathrm{R}$ & $\mathrm{S}$ & $\mathrm{R}$ \\
\hline L. plantaraum A17 & $\mathrm{R}$ & $\mathrm{R}$ & $S$ & $\mathrm{~S}$ & $\mathrm{R}$ & $\mathrm{R}$ & MS & $\mathrm{R}$ & $\mathrm{S}$ & $\mathrm{R}$ \\
\hline L. plantaraum B7 & S & $\mathrm{R}$ & S & $\mathrm{S}$ & S & $\mathrm{R}$ & $\mathrm{R}$ & $\mathrm{R}$ & $\mathrm{S}$ & $\mathrm{R}$ \\
\hline L. plantaraum B19 & S & $\mathrm{R}$ & S & $\mathrm{S}$ & $\mathrm{R}$ & $\mathrm{R}$ & $\mathrm{R}$ & $\mathrm{S}$ & $\mathrm{S}$ & $\mathrm{R}$ \\
\hline L. plantaraum $\mathrm{D} 13$ & $\mathrm{R}$ & $\mathrm{R}$ & S & $\mathrm{S}$ & S & $\mathrm{R}$ & MS & $\mathrm{R}$ & $\mathrm{S}$ & $\mathrm{R}$ \\
\hline L. hilgradii D8 & $\mathrm{R}$ & $\mathrm{R}$ & $S$ & $\mathrm{~S}$ & $\mathrm{R}$ & $\mathrm{R}$ & MS & $\mathrm{R}$ & $\mathrm{S}$ & $\mathrm{R}$ \\
\hline W. paramesenteroides $\mathrm{ClO}$ & $\mathrm{R}$ & MS & S & $\mathrm{S}$ & $\mathrm{S}$ & $\mathrm{R}$ & MS & $\mathrm{R}$ & $\mathrm{S}$ & $\mathrm{R}$ \\
\hline
\end{tabular}

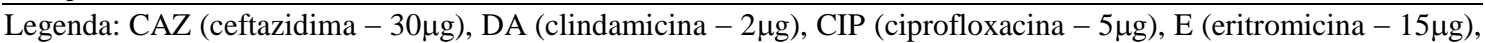

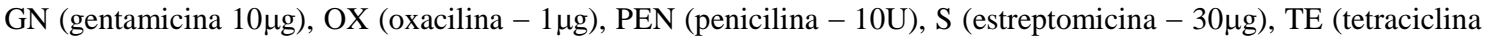
$-30 \mu \mathrm{g}$ ), VA (vancomicina $-30 \mu \mathrm{g})$. $\mathrm{R}=$ resistente; $\mathrm{MS}=$ moderadamente sensível; $\mathrm{S}=$ sensível.

A resistência à vancomicina em $100 \%$ das amostras de Lactobacillus e Weissella testadas foi também observada em outros trabalhos (Coppola et al., 2005; Ouoba et al., 2008; Rodríguez-Alonso et al., 2009), o que confirma que Lactobacillus e outros gêneros de bactérias ácido-láticas podem ter resistência intrínseca à vancomicina (Teuber et al., 1999). Apenas duas amostras (L. plantarum, amostras B7 e B19) foram sensíveis à ceftazidima, e as demais se mostraram resistentes a este antimicrobiano $(83,33 \%)$. Cebeci e Gurakam (2003) observaram que $64 \%$ das suas amostras foram resistentes a este antimicrobiano.

Em concordância com os resultados encontrados neste trabalho, diversos autores encontraram altas porcentagens de resistência à oxacilina em estudos que avaliaram a susceptibilidade a este antimicrobiano (Coppola et al., 2005; RodríguezAlonso et al., 2009). Mesmo pertencendo ao grupo dos $\beta$-lactâmicos, geralmente as taxas de resistência à oxacilina são maiores do que para penicilina (Teuber et al., 1999). Neste trabalho, $33 \%$ das amostras de bactérias ácido-lácticas foram resistentes à penicilina e $100 \%$ à oxacilina. Essa resistência aos $\beta$-lactâmicos pode ser explicada pela possível impermeabilidade da parede celular das bactérias ou pela produção e ação de $\beta$-lactamases (Charteris et al., 1998a).

Para os aminoglicosídeos testados (gentamicina e estreptomicina), a grande maioria das amostras $(91,66 \%)$ foi resistente à estreptomicina, e 
$41,67 \%$ das amostras de lactobacilos à gentamicina. Charteris et al. (1998a) relataram que todas as amostras avaliadas foram resistentes a estes antimicrobianos. Com relação ao antimicrobiano ciprofloxacina, houve elevada taxa de resistência - $75 \%$ das amostras apresentaram resistência. Charteris et al. (1998a) e Ouoba et al. (2008) relataram resultado semelhante, corroborando os resultados encontrados no presente estudo.

As amostras L. rhamnosus B4, W. paramesenteroides $\mathrm{C} 10$ e L. rhamnosus D1 apresentaram resistência a menor número de antimicrobianos testados (ceftazidima, oxacilina, estreptomicina e vancomicina), enquanto as amostras que apresentaram maior resistência aos antimicrobianos foram $L$. casei B5 e $L$. rhamnosus A23. Para selecionar com segurança amostras de bactérias com potencial probiótico, é importante determinar não só o fenótipo de resistência, mas também se os genes que conferem resistência estão presentes e se podem ser transferidos para outras bactérias.

Os resultados referentes aos testes de antagonismo contra microrganismos indicadores das amostras de bactérias ácido-láticas isoladas de queijo-de-minas artesanal da Serra da Canastra são apresentados na Tab. 2.

Tabela 2. Resultados (médias dos diâmetros de halos de inibição em milímetros obtidos de três repetições) dos testes de antagonismo in vitro de bactérias ácido-láticas contra microrganismos indicadores

\begin{tabular}{llllllll}
\hline \multirow{2}{*}{ Amostras produtoras } & \multicolumn{7}{c}{ Microrganismos indicadores } \\
\cline { 2 - 7 } & $\mathrm{A}$ & $\mathrm{B}$ & $\mathrm{C}$ & $\mathrm{D}$ & $\mathrm{E}$ & $\mathrm{F}$ & $\mathrm{G}$ \\
\hline L. plantarum A17 & $0 \mathrm{a}$ & $0 \mathrm{a}$ & $0 \mathrm{a}$ & $37,04 \mathrm{~b}$ & $73,82 \mathrm{~b}$ & $56,18 \mathrm{~b}$ & $35,75 \mathrm{~b}$ \\
L. casei A21 & $0 \mathrm{a}$ & $0 \mathrm{a}$ & $0 \mathrm{a}$ & $37,27 \mathrm{~b}$ & $67,10 \mathrm{~b}$ & $48,68 \mathrm{~b}$ & $33,82 \mathrm{~b}$ \\
L. rhamnosus A23 & $0 \mathrm{a}$ & $0 \mathrm{a}$ & $0 \mathrm{a}$ & $47,90 \mathrm{~b}$ & $60,87 \mathrm{~b}$ & $57,13 \mathrm{~b}$ & $42,03 \mathrm{~b}$ \\
L. rhamnosus B4 & $3,53 \mathrm{a}$ & $0 \mathrm{a}$ & $0 \mathrm{a}$ & $41,20 \mathrm{~b}$ & $64,21 \mathrm{~b}$ & $45,12 \mathrm{~b}$ & $23,01 \mathrm{~b}$ \\
L. casei B5 & $0 \mathrm{a}$ & $0 \mathrm{a}$ & $0 \mathrm{a}$ & $47,07 \mathrm{~b}$ & $66,16 \mathrm{~b}$ & $55,95 \mathrm{~b}$ & $32,47 \mathrm{~b}$ \\
L. plantarum B7 & $3,19 \mathrm{a}$ & $0 \mathrm{a}$ & $0 \mathrm{a}$ & $32,24 \mathrm{~b}$ & $71,38 \mathrm{~b}$ & $61,41 \mathrm{~b}$ & $24,42 \mathrm{~b}$ \\
L. plantarum D13 & $0 \mathrm{a}$ & $0 \mathrm{a}$ & $0 \mathrm{a}$ & $36,43 \mathrm{~b}$ & $73,77 \mathrm{~b}$ & $41,93 \mathrm{~b}$ & $34,54 \mathrm{~b}$ \\
L. plantarum B19 & $2,85 \mathrm{a}$ & $5,16 \mathrm{a}$ & $0 \mathrm{a}$ & $57,11 \mathrm{~b}$ & $74,48 \mathrm{~b}$ & $63,16 \mathrm{~b}$ & $49,99 \mathrm{~b}$ \\
L. casei C7 & $0 \mathrm{a}$ & $0 \mathrm{a}$ & $0 \mathrm{a}$ & $33,91 \mathrm{~b}$ & $45,52 \mathrm{~b}$ & $41,74 \mathrm{~b}$ & $20,98 \mathrm{~b}$ \\
W. paramesenteroides $\mathrm{C} 10$ & $0 \mathrm{a}$ & $0 \mathrm{a}$ & $0 \mathrm{a}$ & $51,57 \mathrm{~b}$ & $60,63 \mathrm{~b}$ & $59,16 \mathrm{~b}$ & $29,64 \mathrm{~b}$ \\
L. rhamnosus D1 & $0 \mathrm{a}$ & $5,57 \mathrm{a}$ & $0 \mathrm{a}$ & $41,87 \mathrm{~b}$ & $62,64 \mathrm{~b}$ & $49,32 \mathrm{~b}$ & $48,08 \mathrm{~b}$ \\
L. hilgardii D8 & $0 \mathrm{a}$ & $0 \mathrm{a}$ & $0 \mathrm{a}$ & $34,91 \mathrm{~b}$ & $72,78 \mathrm{~b}$ & $60,29 \mathrm{~b}$ & $38,04 \mathrm{~b}$ \\
\hline
\end{tabular}

Legenda: $\mathrm{A}=$ Lactococcus $\mathrm{sp} . \mathrm{B} 12, \mathrm{~B}=$ L. rhamnosus $\mathrm{B} 25, \mathrm{C}=$ L. fermentum ATCC9338, D = Escherichia coli ATCC 25922, $\mathrm{E}=$ L. monocytogenes ATCC 15313, $\mathrm{F}=S$. Typhimurium ATCC $14028 \mathrm{e} \mathrm{G}=$ S. aureus ATCC 29313; Resultados seguidos por letras minúsculas distintas na mesma linha são diferentes $(\mathrm{P}<0,05)$ pelo teste de KruskalWallis.

Amostras de microrganismos isolados de queijode-minas artesanal da Serra da Canastra apresentaram médias de halos de inibição maiores $(\mathrm{P}<0,05)$ ante bactérias patogênicas em comparação às bactérias ácido-láticas isoladas dos mesmos queijos (Tab. 2). Não houve diferença $(\mathrm{P}>0,05)$ entre as médias dos halos de inibição em relação aos microrganismos indicadores não patogênicos isolados dos queijos (bactéria ácido-láticas B12 e B25) e $L$. fermentum ATCC9338.

Uma baixa atividade inibitória das bactérias produtoras analisadas contra outras bactérias ácido-láticas é esperada, tendo em vista os resultados encontrados por outros pesquisadores (Alexandre et al., 2002; Hajikhani et al., 2007), o que possibilitará a utilização dessas bactérias testadas associadas com outras bactérias ácidoláticas, ampliando, assim, a sua ação inibitória contra outros microrganismos.

Não houve diferença $(\mathrm{P}>0,05)$ entre as médias dos diâmetros dos halos de inibição das amostras produtoras em relação às amostras reveladoras patogênicas $E$. coli ATCC 25922, $L$. monocytogenes ATCC 15313, S. typhimurium ATCC 14028 e $S$. aureus ATCC 29313. Foi evidenciado resultado semelhante em outras pesquisas, com ampla atividade inibitória de 
Lactobacillus spp. e outras bactérias ácido-láticas contra os gêneros de microrganismos patogênicos estudados neste trabalho (Garde et al., 2001; Alexandre et al., 2002; Hajikhani et al., 2007).

Embora tenha sido evidente o antagonismo, a menor inibição dos microrganismos indicadores patogênicos ocorreu contra $S$. aureus ATCC 29313. Esse fato pode ter relação com resultados das análises microbiológica dos queijos-de-minas artesanais da Serra da Canastra estudados (Resende et al., 2011), visto que, dos microrganismos patogênicos pesquisados, apenas Staphylococcus spp. foi encontrado em elevadas concentrações $\left(1,7 \times 10^{8} \mathrm{UFC} / \mathrm{g}\right)$. São necessários maiores estudos para entender a relação entre as bactérias ácido-láticas e Staphylococcus spp.
Ao se analisarem as possíveis substâncias responsáveis pela inibição, o ácido lático provavelmente é a mais importante no caso dos microrganismos avaliados neste trabalho. Quando o ácido lático é produzido por esses microrganismos, o metabolismo das bactérias sensíveis é alterado, causando efeito bacteriostático ou bactericida (Grajek et al., 2005). A produção de bacteriocinas também pode ser responsável pela inibição. Outros autores apresentam casos em que Lactobacillus spp. demonstraram atividade inibitória frente a outros microrganismos (Garde et al., 2001; Caridi, 2002).

Os resultados referentes aos testes de sensibilidade a $\mathrm{pH}$ gástrico e sais biliares de 12 amostras de bactérias ácido-láticas isoladas de queijo-de-minas artesanal da Serra da Canastra são apresentados na Tab. 3.

Tabela 3. Percentual de inibição de 12 amostras de bactérias ácido-láticas isoladas de queijo-de-minas artesanal da Serra da Canastra, em pH gástrico e sais biliares, nos tempos seis e 12 horas de crescimento

\begin{tabular}{lcccc}
\hline \multirow{2}{*}{ Amostras } & \multicolumn{2}{c}{ \% inibição $\mathrm{pH}$ gástrico } & \multicolumn{2}{c}{ \% inibição sais biliares } \\
\cline { 2 - 5 } & $6 \mathrm{~h}$ & $12 \mathrm{~h}$ & $6 \mathrm{~h}$ & $12 \mathrm{~h}$ \\
\hline L. casei A21 & 32,74 & 19,68 & 78,35 & 80,86 \\
L. casei B5 & 03,16 & 00,00 & 82,12 & 81,06 \\
L. casei C7 & 00,00 & 00,00 & 59,42 & 69,80 \\
L. rhamnosus A23 & 58,70 & 05,02 & 70,29 & 73,10 \\
L. rhamnosus B4 & 27,93 & 10,99 & 62,40 & 67,24 \\
L. rhamnosus D1 & 00,00 & 08,10 & 79,80 & 77,64 \\
L. plantarum A17 & 17,55 & 02,55 & 88,81 & 89,73 \\
L. plantarum B7 & 18,86 & 18,99 & 42,95 & 33,74 \\
L. plantarum B19 & 00,00 & 00,00 & 14,82 & 04,74 \\
L. plantarum D13 & 04,47 & 00,00 & 27,89 & 46,31 \\
L. hilgardii D8 & 16,62 & 10,06 & 88,81 & 89,73 \\
W. paramesenteroides C10 & 01,19 & 01,95 & 62,20 & 66,13 \\
\hline
\end{tabular}

Após o tratamento em acidez equivalente a do estômago humano (pH 2) e em pH neutro (7 controle), os resultados demonstraram que as amostras de bactérias ácido-láticas apresentaram pouca variação no crescimento (Tab. 3). Como essas bactérias ácido-láticas foram isoladas de um ambiente em que predomina a acidez, visto que no processo de produção dos queijos o pH baixo é frequente (Resende et al., 2011), foi esperado que esses microrganismos fossem adaptados às condições de estresse gerado pela elevada acidez. Adicionalmente, são microrganismos que produzem ácido lático e, provavelmente, precisam apresentar resistência a esse ácido para garantir sua sobrevivência nos queijos (Gilliland, 1985).

Os resultados encontrados estão de acordo com o observado por Vinderola e Reinheimer (2003), pois bactérias ácido-láticas probióticas apresentaram maior resistência a $\mathrm{pH}$ baixo que outras bactérias ácido-láticas. Isto sugere a possibilidade de utilização dessas bactérias potencialmente probióticas. Entre as amostras, aquelas que obtiveram melhor desempenho, $L$. casei C7 e L. plantarum B19, não demonstraram inibição pelo baixo $\mathrm{pH}$ em nenhum dos dois tempos. 
A resistência à ação do ácido clorídrico é importante porque este se difunde através da membrana celular e depois no citoplasma, dissociando-se e liberando prótons. O acúmulo de prótons no meio intracelular pode interferir no funcionamento da membrana celular, prejudicando processos essenciais à sobrevivência celular (Guchte et al., 2002).

No teste de sensibilidade a sais biliares, houve grande variação no resultado, sendo observadas amostras, em sua maioria, sensíveis (Tab. 3). A variabilidade de susceptibilidade a sais biliares de bactérias ácido-láticas isoladas de diferentes origens foi também observada por Chateau et al. (1994) e Vinderola e Reinheimer (2003).

A amostra que obteve melhor desempenho no teste foi L. plantarum B19, apresentando inibição menor que $15 \%$. As amostras L. plantarum B7 e L. plantarum D13 obtiveram bom desempenho, com inibição menor que $50 \%$ nos tempos observados (Tab. 3). É possível que estes microrganismos tenham sido naturalmente selecionados após passarem por processo de digestão no trato gastrintestinal (Chateau et al., 1994).

Vinderola e Reinheimer (2003) observaram que amostras probióticas possuem resistência maior a sais biliares que bactérias ácido-láticas "starters", porém, mesmo sendo probióticos, os microrganismos sofrem algum percentual de inibição do crescimento pelos sais biliares.

As amostras que obtiveram maior inibição do crescimento na presença de sais foram $L$. casei A21, B5, C7; L. hilgardii D8; L. plantarum A17; rhamnosus A23, B4, D1 e W. paramesenteroides C10 (Tab. 3). Estas amostras foram inibidas, mas permaneceram viáveis durante todo o período de análise. Isto possibilitaria a sua utilização como probióticos, desde que a concentração encontrada no sítio de ação fosse elevada $\left(>10^{7} \mathrm{UFC} / \mathrm{g}\right)$ (Charteris et al., 1998b). A sensibilidade a sais biliares no intestino delgado ocorre, principalmente, pela ação detergente deles à membrana celular constituída de lipídeos e ácidos graxos das bactérias (Guchte et al., 2002).

Os microrganismos que mostraram sensibilidade a maior número de antimicrobianos tiveram preferência na seleção diante dos demais: $L$. rhamnosus B4, W. paramesenteroides $\mathrm{C} 10$ e $L$. rhamnosus D1 apresentaram resistência a menor número de antimicrobianos (Tab. 1). O tipo de resistência poderia ser pesquisado ao nível molecular a fim de se verificar se ela é intrínseca, ou seja, cromossômica ou não. Além disso, testes que avaliem a susceptibilidade destas amostras a outros antimicrobianos também poderiam ser realizados, pois a mesma amostra pode ter resistência variada a antimicrobianos de um mesmo grupo (Charteris et al., 1998a). Estas três amostras demonstraram ser antagonistas a microrganismos indesejáveis, mas não inibiram microrganismos desejáveis $(\mathrm{P}<0,05)$. Isto possibilitaria o desenvolvimento de diferentes culturas lácticas probióticas para elaboração de produtos potencialmente funcionais. $\mathrm{Com}$ relação à sensibilidade ao pH gástrico, as três amostras selecionadas obtiveram resultado satisfatório, sendo pouco inibidas pela acidez. Com isso, teoricamente, estes microrganismos estariam aptos a sobreviverem ao ambiente gástrico, chegando ao intestino com maior número de células viáveis, o que favoreceria seu efeito probiótico. As amostras citadas foram inibidas, mas se mantiveram viáveis durante todo o teste de sensibilidade a sais biliares, visto que apresentaram crescimento no tempo limite de $12 \mathrm{~h}$ do teste. Como o tempo de trânsito no intestino delgado não é superior a seis horas, é possível que parte destes microrganismos permaneça viável até o sítio de ação para desempenhar suas características probióticas, desde que seja ingerida em concentrações adequadas (Charteris et al., 1998b; FAO/WHO, 2002).

A partir da seleção de amostras potencialmente probióticas, a utilização desses microrganismos para a elaboração de queijos com as características sensoriais próximas às dos queijos artesanais poderá ser viável, com a vantagem de se ter o conhecimento das culturas lácteas envolvidas no processo de produção. A transferência da tecnologia para que os produtores atuais possam aprimorar o produto sem perder a tradição do queijo de Minas é desejável.

\section{CONCLUSÕES}

Queijo-de-minas artesanal da Serra da Canastra pode veicular microrganismos com potencial probiótico para os consumidores. $\mathrm{O}$ antagonismo $\mathrm{e}$ a sensibilidade in vitro a $\mathrm{pH}$ gástrico 
foram menos seletivos quando comparados à susceptibilidade a antimicrobianos e à sensibilidade in vitro a sais biliares, o que possibilitou uma seleção mais rigorosa das amostras por estes dois últimos testes. As amostras L. rhamnosus B4, W. paramesenteroides $\mathrm{C} 10$ e L. rhamnosus D1 seriam candidatas à elaboração de novas culturas lácteas para produção de produtos lácteos fermentados potencialmente funcionais, podendo auxiliar na segurança alimentar e na preservação da microbiota original de queijos artesanais de Minas Gerais.

\section{AGRADECIMENTOS}

À Fundação de Amparo à Pesquisa do Estado de Minas Gerais (Fapemig), pelo auxílio financeiro.

\section{REFERÊNCIAS}

ALEXANDRE, D.P.; SILVA, M.R.; SOUZA, M.R.; SANTOS, W.L.M. Atividade antimicrobiana de bactérias lácticas isoladas de queijo de minas artesanal do Serro (MG) frente a microrganismos indicadores. Arq. Bras Med. Vet. Zootec., v.54, p.424-428, 2002.

ANVISA, Agência Nacional de Vigilância Sanitária. Normas de desempenho para testes de sensibilidade antimicrobiana: $15^{\circ}$ Suplemento Informativo, v.25, p.55-58, 2005.

ANVISA, Agência Nacional de Vigilância Sanitária. Alimentos com Alegação de Propriedades Funcionais $e$ ou Saúde, Novos Alimentos/ Ingredientes, Substâncias Bioativas e Probióticos, 2008.

CARIDI, A. Selection of Escherichia coli-inhibiting strains of Lactobacillus paracasei subsp. paracasei. J. Ind. Microbiol. Biotechnol., v.29, p.303-308, 2002.

CEBECI, A.; GURAKAN, C. Properties of potential probiotic Lactobacillus plantarum strains. Food Microbiol., v.20, p.511-518, 2003.

CHARTERIS, W.P.; KELLY, P.M.; MORELLI, L.; COLLINS, K. Antibiotic susceptibility of potential probiotic Lactobacillus species. J. Food Protect., v.61, p.1636-1643, 1998a.

CHARTERIS, W.P.; KELLY, P.M.; MORELLI, L.; COLLINS, K. Development and application of an in vivo methodology to determine the transit tolerance of potentially probiotic Lactobacillus and Bifidobacterium species in the upper human gastrointestinal tract. J. Appl. Microbiol., v.84, p.759768,1998 b.
CHATEAU A.N.; DESCHAMPS, M.; HADJ SASSI, A. Heterogeneity of bile salts resistance in the Lactobacillus isolates of a probiotic consortium. Lett. App. Microbiol., v.18, p.42-44, 1994.

COPPOLA, R.; SUCCI, M.; TREMONTE, P.; REALE, A. et al. Antibiotic susceptibily of Lactobacillus rhamnosus strains isolated from Parmigiano Reggiano cheese. Lait, v.85, p.193-204, 2005.

FAO/WHO. (Ed.) Guidelines for the evaluation of probiotics in food. Canada, 2002.11p.

GARDE, S.; RODRIGUES, E.; GAYA, P. et al. PCR detection of the structural genes of nisin $\mathrm{Z}$ and lacticin 481 in Lactococcus lactis subsp. lactis INIA 415, a strain isolated from raw milk Manchego cheese. Biotechnol. Lett., v.23, p.85-89, 2001.

GILLILAND, S.E. (Ed). Bacterial Starter Cultures for Food. EUA: CRC, 1985. 175p.

GRAJEK, W.; OLEJNIK, A.; SIP, A. Probiotics, prebiotics and antioxidants as functional foods. Acta Biochim. Pol., v.52, p.665-671, 2005.

GUCHTE, M.; SERROR, P.; CHERVAUX, C. et al. Stress responses in lactic acid bacteria. Ant. Leeuw. J., v.82, p.187-216, 2002.

HAJIKHANI, R.; BEYATLI, Y.; BELMA ASLIM, B. Antimicrobial activity of enterococci strains isolated from white cheese. Int. J. Dairy Technol., v.60, p.105108, 2007.

MOTA, R.M.; MOREIRA, J.L.S.; SOUZA, M.R. et $a l$. Genetic transformation of novel isolates of chicken Lactobacillus bearing probiotic features for expression of heterologous proteins: a tool to develop live oral vaccines. BMC Biotechnol., v.6, 2, 2006.

OUOBA, L.I.I.; LEI, V.; JENSEN, L.B. Resistance of potencial probiotic lactic acid bacteria and of African and European origin to antimicrobials: Determination and transferability of the resistance genes to other bacteria. Int. J. Food Microbiol., v.121, p. 217-224, 2008.

RESENDE, M.F.S.; COSTA, H.H.S.; ANDRADE, E.H.P. et al. Queijo-de-minas artesanal da Serra da Canastra: influência da altitude das queijarias nas populações de bactérias ácido-lácticas. Arq. Bras. Med. Vet. Zootec., v.63, p.1532-1538, 2011.

RODRÍGUEZ-ALONSO, P.; FERNÁNDEZ-OTERO, C.; CENTENO, J.A.; GARABAL, J.I. Antibiotic resistance in lactic acid bacteria and Micrococcaceae/Staphylococcaceae isolates from artisanal raw milk cheeses, and potential implications on cheese making. J. Food Sci., v.74, p.284-293, 2009. 
SAMPAIO, I.B.M. (Ed.) Estatística Aplicada à Experimentação Animal. Brasil: Fundação de Ensino e Pesquisa em Medicina Veterinária e Zootecnia, 2002. 265p.

TAGG, J.R.; DAJANI, A.S.; WANNAMAKER, L.W. Bacteriocin of Gram positive bacteria. Bact. Rev. v.40, p.722-756, 1976.

TEUBER, M.; MEILE, L.; SCHWARZ, F. Acquired antibiotic resistance in lactic acid bacteria from food. Ant. Leeuw. J., v.76, p.115-137, 1999.

TISALA-TIMISJARVI, A.; ALATOSSAVA, T. Development of oligonucleotide primers from the
16S-23S rDNA intergenic sequences for identifying different dairy and probiotic lactic acid bacteria by PCR. Int. J. Food Microbiol., v.35, p.49-56, 1997.

VINDEROLA, C.G.; REINHEIMER, J.A. Lactic acid starter and probiotic bacteria: a comparative "in vitro" study of probiotic characteristics and biological barrier resistance. Food Res. Int., v.36, p.895-904, 2003.

WALKER, D.K.; GILLILAND, S.E. Relationships among bile tolerance, bile salt deconjugation, and assimilation of cholesterol by Lactobacillus acidophilus. J. Dairy Sci., v.76, p.956-961, 1993. 